\title{
474981 - PROPANOLOL DECREASES PAIN PERCEPTION IN HEALTHY VOLUNTEERS
}

\author{
Elena Gramigni, MD ${ }^{1}$, Petra Schweinhardt, MD $^{2}$, G. Baldini, MD ${ }^{1}$, A. Clemente, \\ $\mathrm{MD}^{1}$, M. Bushnell, $\mathrm{MD}^{2}$, Franco Carli, $\mathrm{MD}^{1}$ \\ 1. Anesthesia, McGill, Montreal, QC, Canada \\ 2. Centre for research in pain, McGill, Montreal, QC, Canada
}

Introduction: The potential usefulness of beta-adrenergic antagonists in the treatment of acute pain has been suggested by studies using the beta-1-receptor antagonist esmolol as an adjunct agent in perioperative management. Here, we investigated if the lipophilic mixed beta blocker propanolol reduces nociceptive pain in healthy subjects.

Methods: Local REB approval was obtained for this study. Twenty male volunteers took part in a randomized, double-blind, placebo-controlled crossover trial. Painful heat stimuli were applied to the volar forearm before (Time 0), between 5 and 20 min (Time 1), 25 and 30 min (Time 2), and 35 and 40 min (Time 3) after drug administration. Heat stimuli were applied using a $9 \mathrm{~cm} 2$ thermode (Medoc TSA-II NeuroSensory analyzer, Medoc Ltd Advanced Medical System, Israel) at a temperature of 45 - $49{ }^{\circ} \mathrm{C}$ to elicit pain of 70/100 on a VAS before drug administration. Temperatures were held constant for each subject throughout the study. Following a 20 minute rest period, propanolol 0.3 $\mathrm{mg} / \mathrm{kg}$ or normal saline were injected intravenously. ECG, oxygen saturation and blood pressure were recorded throughout the experiments and VAS ratings acquired at Time 0 , 1,2 , and 3. Heart rate and VAS data were analyzed using ANOVA for repeated measures, followed by simple contrasts.

Results: The main effect of time was significant for the propanolol condition [F (2.1, $38.3)=8.82, \mathrm{P}=0.001$ ], indicating that propanolol had a significant analgesic effect. The pain ratings were reduced from a mean of $70.2(\mathrm{SD}=2.9)$ at Time 0 to a mean of 62.3 $(\mathrm{SD}=8.4, \mathrm{P}<0.001)$ at Time 1 . The reduction was maintained at Time $2(\mathrm{M}=64.6, \mathrm{SD}=9.3$, $\mathrm{P}<0.01)$ and Time $3(\mathrm{M}=65.1, \mathrm{SD}=9.7, \mathrm{P}<0.05)$. There was no difference of pain scores at Time 1, 2, and 3. The main effect of time was not significant for the saline condition $(\mathrm{F}(2.4,43.3)=8.82, \mathrm{P}=0.1)$. The heart rate results mirrored those of the VAS scores [main effect of time: $\mathrm{F}(2.4,43.7)=39.2, \mathrm{P}<0.001$ in the propanolol condition and $\mathrm{F}(2.4,43.7)=1.38, \mathrm{P}=0.26$ in the saline condition]. For further analysis, subjects were subdivided into propanolol responders and non-responders according to their heart rate response. The responders showed a trend for a greater decrease of VAS ratings following propanolol administration compared to the non-responders $[\mathrm{F}(1,17)=3.4, \mathrm{P}=0.08]$.

Discussion: Our findings show that propanolol reduces pain induced by experimental heat stimuli in healthy volunteers. The reduction of pain ratings was accompanied by a reduction in heart rate as expected following propanolol. Heart rate responders showed a non-significant trend for a greater effect of propanolol on pain perception compared to non-responders. It remains to be clarified if the analgesic effect of propanolol is independent of its effect on heart rate.

References: none 